\title{
Response to "Continental drift? Do European clinical genetic testing laboratories have a patent problem?"
}

\author{
Carsten D. Richter ${ }^{1}$
}

Received: 17 October 2019 / Revised: 13 December 2019 / Accepted: 4 February 2020 / Published online: 17 February 2020

(c) European Society of Human Genetics 2020

\section{To the Editor:}

In the March issue of the European Journal of Human Genetics, Liddicoat et al. [1] analyze the impact of generelated patents on European clinical genetic laboratories, based on a study with responses from 158 diagnostic laboratories. They conclude that diagnostic laboratories in the nonprofit sector are increasingly affected by the impact of patents pertaining to genetic testing and suggest that legal support be provided for such institutions.

The authors deserve credit for addressing this important topic and for making a valiant effort to collect relevant data. Their results will be of significant interest both to the scientific community and intellectual property (IP) specialists. I do not agree with their conclusion that legal support for nonprofit sector laboratories should be publicly funded though.

First of all, there appears to be no need for such support at least at present. While the proportion of nonprofit laboratories that have refrained from performing a test may have increased over the past 10 years, this increase is on a fairly low absolute level (by 8-15\%) and means that only one in eight laboratories is affected at all. It should also be borne in mind that having to refrain from performing a single test is not necessarily a significant limitation of the services of a laboratory. Therefore, the impact of patents is even lower than suggested by the data presented.

The authors are right to point out that a key consideration should be that patients can obtain test results from at least one lab. As far as I am aware, no one has ever blocked access to a diagnostic test by enforcing a patent in a European country.

Carsten D. Richter

c.richter@euroimmun.de

1 EUROIMMUN Medizinische Labordiagnostika AG, Seekamp 31, 23567 Lübeck, Germany
Second, it is unclear how legal support would actually be provided. While major US medical centers diagnosing and treating more than a million patients each year have their own legal departments, the European market is dominated by a diversity of small service providers whose revenues do not justify the employment of in-house attorneys. Therefore, European laboratories have to rely on external counsels. In theory, it may be possible for research councils to put up specific grants for funding such advice. Laboratories could then apply for support if contacted by a patentee threatening to enforce a patent against them. But, in practice, the review of such applications, possibly by both a scientist and a legally qualified reviewer, would likely take several months, while a response to a warning letter may have to be submitted within no more than 3 weeks [2]. Not in the least, fees for attorneys and courts depend on how the case develops and it is difficult to provide a forecast in advance. Overall, a grant-based support system would be too slow and insufficiently flexible.

It could be argued that laboratories in European countries with a limited number of biotech companies may find it particularly difficult to defend themselves against attacks than laboratories in other countries due to a shortage of funds and experience in IP proceedings. However, considerably fewer patents are filed in such countries, which means that the risk of litigation is much lower. For example, in Germany, France and the UK, at total of 94,614, 26,660, and 26,675 patents, respectively, were filed in 2018, while only 699, 911, and 150 were filed in Greece, Portugal, and Croatia [https://www.wipo.int/ipstats/en/statistics/country_ profile]. In fact, the vast majority of infringement proceedings are handled by German courts [3]. Overall, the risk of being sued for patent infringement is a real threat only in countries with thriving biotech companies and specialized IP courts.

Liddicoat et al. propose that general information as to whether laboratories have freedom to operate regarding a certain diagnostic test could be organized and disseminated through public institutions such as health departments, 
patent offices, or academic publications. However, laboratories usually develop their own optimized assays, and any legal advice must be tailored to the specific reagents they use. After all, slightly modifying a patented nucleic acid sequence could be sufficient to design around a patent, so general advice is of limited value. For example, claim 6 of European patent 0705902 B1 (BRCA1 gene-related cancer diagnostics) is directed to a nucleic acid probe the sequence of which comprises the DNA sequence set forth in SEQ ID NO1 from nucleotide position 3631-3930. A competitor of the patentee may be able to design around this patent claim if he succeeds in practicing the invention using a nucleic acid probe that lacks nucleotide 3631 , but comprises 3632-3930 only.

Moreover, public institutions have specific jobs, and providing specific legal advice is not one of them. For example, the European Patent Convention is intended for the grant of patents [4]. Hence, the European Patent Office has funds and staff to examine patents, but not to advise on patent infringement. In fact, only chartered attorneys organized in law firms are entitled to do so in many countries.

Finally, privately owned laboratories have to consider IP risks before introducing a new test, reserve funds for potential legal disputes and pass the costs to their customers, and it is not clear why public laboratories should not be able to do the same. Public funds available for public sector laboratories, but not for private laboratories would not only reward the irresponsible who make no effort to analyze third party IP before introducing a test, but also distort competition, which is so important as it adds to the variety and quality of services offered and lowers test prices, thus making diagnostic services more affordable.

In any event, I do agree with the authors that there is room for improving the availability of certain general patent-related information via public channels. For example, if a patent is identified as relevant, it should be possible for a layman in the field of IP to check on a webpage in English maintained by the responsible patent office whether the patent is still active and when the latest possible date of expiry will be. Essential nucleic acid and polypeptide sequences referred to in the patent claims should be downloadable for no charge in an electronically readable format. Such services have yet to established by many patent offices, would allow scientists to monitor patents without consulting with a patent attorney and would reduce the costs for managing the risk of patent infringement for public and private laboratories alike.

\section{Compliance with ethical standards}

Conflict of interest The author is a patent attorney employed by a company that manufactures and commercializes diagnostic reagents and holds and in-licenses patents protecting such reagents and related methods.

Publisher's note Springer Nature remains neutral with regard to jurisdictional claims in published maps and institutional affiliations.

\section{References}

1. Liddicoat J, Liddell K, McCarthy AH, Hogarth S, Aboy M, Nicol $\mathrm{D}$, et al. Continental drift? Do European clinical genetic testing laboratories have a patent problem? Eur J Hum Gen. 2019;27:997-1007.

2. Kühnen T. Handbuch der Patentverletzung. 12th ed. Köln: Carl Heymanns Verlag; 2019.

3. Cremers K, Ernicke M, Gaessler F, Harhoff D, Helmer C, McDonagh L, et al. Patent litigation in Europe, ZEW Discussion Paper No 13-072 2013, www.ftp.zew.de.

4. European Patent Convention, Article 1. 